\title{
Chapter 8 \\ School Development in South \\ Carolina - Building Leadership Capacity for Evidence-Based School Development in South Carolina Schools
}

\author{
Peter Moyi, Suzy Hardie, and Kathleen M. W. Cunningham
}

\begin{abstract}
This study presents two U.S. school development projects aimed at building leadership capacity for continuous school development that attempts to use "evidence-based" ideas from the standpoint of education values and understandings with a renewed sensitivity to culturally diverse students in South Carolina schools. The Lowcountry Educator Initiative (LEI) uses a professional development program designed for educators from various schools. School Improvement through Improvement Science (SITIS), stems from a larger university-school partnership initiative that includes other institutions around the United States. The two projects serve as compelling examples that push on the limited scope that federal and local policy requirements place on educational institutions to provide evidence of improvements that lead to educational success. This work offers qualitative evidence that honors, recognizes, and leverages the strengths of the participants' contexts to facilitate improvement in practice. The projects implemented offer evidence for (1) providing leadership support for school improvement efforts, (2) the use of local context in improving practice, and (3) the valuing of various data to engage in locally-relevant and appropriate work. We recommend centering the local context and improvement science approaches in research design, research funding, and educator preparation.
\end{abstract}

Keywords Place-based education · Improvement science · Leadership development $\cdot$ Educational equity

P. Moyi $(\bowtie) \cdot$ S. Hardie $\cdot$ K. M. W. Cunningham

University of South Carolina, Columbia, SC, USA

e-mail: moyi@mailbox.sc.edu; sehardie@mailbox.sc.edu; katiemwc@mailbox.sc.edu 


\section{Introduction to the Chapter's Purpose}

This study presents two U.S. school development projects aimed at building leadership capacity for continuous school development that attempts to use "evidencebased" ideas from the standpoint of education values and understandings with a renewed sensitivity to culturally diverse students in South Carolina schools. The aim is to help schools mitigate the gaps in educational opportunities experienced by culturally diverse students who have been historically marginalized. The two projects are different and distinct. One project, the Lowcountry Educator Initiative (LEI), uses a professional development program designed for groups of educators from various schools in South Carolina. This project focuses on place-based learning as a vehicle to improve educational opportunity and achievement through instruction that leverages the assets of schools' local communities. The other project, School Improvement through Improvement Science (SITIS), stems from a larger university-school partnership initiative that includes other institutions around the United States. This initiative uses an improvement science (Bryk et al., 2015) framework to address problems of practice in the partner school. Outside these differences, however, the projects are connected in their overarching values and aims and the policy contexts in which they operate. We present findings from semistructured interviews, observations, and fieldnotes that highlight key processes and outcomes related to teacher and leader development including effective organizational structures, professional development processes, and changes in practice. Due to the stages of both projects, we dedicate more attention in this chapter to the LEI.

Through partnerships, both projects help schools (1) build internal professional capacity to address problems of practice, (2) strengthen human connections both within the school as well as with the community, and (3) improve instruction through improving their students' experiences. The two projects serve as compelling examples that push on the limited scope that federal and local policy requirements place on educational institutions to provide evidence of improvements that lead to academic success. Further, many U.S. research funding sources now require the use of prior school improvement models that produced "strong evidence" of improved student outcomes and school development, all of which is currently subject of debate in the literature (e.g. Biesta, 2010; Slavin, 2008). This work offers qualitative evidence, that honors, recognizes, and leverages the strengths of the participants' contexts to facilitate improvement in practice.

In this chapter, we first offer a brief description of the U.S.'s national educational context through a synopsis of federal laws and policies. Next, we focus on one state, South Carolina. This section describes the history of education in the state and how national policy has impacted and continues to impact the education system locally. Following, we offer some challenges stemming from the policy contexts related to school improvement. We then shift focus and describe both the LEI and SITIS, their overlapping purposes, and the lessons learned that shape our recommendations for educational practice and policy moving forward. 


\section{South Carolina Policy Context}

South Carolina was impacted by the federal context policy evolution; and the goal of federal and state policies have been the closure of the achievement gap as described in Chap. 1. The U.S. education system has struggled to address issues of educational inequality. Despite outlawing segregated schools, Black and Latinx students and low-income students attend the most under resourced schools (Orfield et al., 2016). South Carolina has a long history of unequal education with poor rural, mostly minority, students facing the biggest challenge (Tran et al., 2020). The racial divide between White and Black students was evident with the early settlers in South Carolina with a mindset that education was only for affluent white people who could afford a private education through a personal tutor. As a result, poor White and Black students did not receive an education. Education of children of color was formally limited through 1740 s by laws criminalizing teaching Black students to read and write. By 1927 in South Carolina, there were 279 high schools for Whites, but only 10 high schools for Black students (Switzer \& Green, 2016).

South Carolina was slow to institute the 1954 Brown v. Board of Education, the landmark case that made segregation of schooling unlawful. Schools in South Carolina were not desegregated until the 1970-1971 school year (Switzer \& Green, 2016). Even after desegregation major disparities between the education of White and Black students persisted. Funding of schools was not equal between schools with majority White students compared to schools with a majority of Black students. According to the South Carolina Constitution's education clause, the General Assembly must provide a "minimally adequate education" (Tran et al., 2020); unfortunately there are major disparities among school districts.

In 1993, the state of South Carolina was sued by 36 school districts for failing to provide adequate funds for education - Abbeville County School District et al. $v$. the State (Hart, 2015). These school districts are found in a region of the state along Interstate-95 between North Carolina and Georgia. This area became known as the "Corridor of Shame" after the 2006 documentary, Corridor of Shame: The Neglect of South Carolina's Rural Schools by Bud Ferillo. Well-known South Carolina author, Pat Conroy, who had taught Black elementary students on Daufuskie Island in Beaufort County, South Carolina, chronicled his experiences in the memoir, The Water is Wide (1972). Conroy described the neglect of rural students in South Carolina, especially Blacks. In the introduction to the Corridor of Shame documentary, Conroy, argued that the "water is even wider" three decades later, illustrating the justification the rural school districts had in suing the state of South Carolina for not providing adequate funding to offer quality education for its own students.

In 2014, the South Carolina Supreme Court, in the Abbeville County School District et al. v. the State case, ruled that a wide opportunity gap existed in South Carolina due to insufficient state funding. The Court, in essence, told the State to do more to ensure equal opportunity for South Carolinian children. However, in 2017, the Supreme Court vacated the landmark decision that held the state accountable for poor, failing schools citing judicial overreach (Black, 2017). Nevertheless, 
schools are continually and negatively impacted by state funding policies and this case exemplifies the challenge of improving schools in parts of South Carolina.

As South Carolina has not provided equitable opportunities for its students, it is no surprise students' performance ranks among the lowest in the nation. The U.S. News \& World Report ranks South Carolina number 43 out of the 50 states (U.S. News, 2020). Further, since 1998, South Carolina has consistently performed below the national average in NAEP 4th grade reading (NCES, 2020). When the NAEP scores are disaggregated by race and income, the gaps are even more pronounced. For example, in 2019, Black 4th graders had an average reading score that was 31 points lower than their white classmates. At the same time, poor 4th grade students, as measured by those eligible for the National School Lunch Program, scored an average of 32 points lower (NCES, 2020).

Federal policies such as NCLB, Race to the Top, and ESSA, reflect a paradigm of school leadership defined by performance outcomes and standardization. Under ESSA, states have more flexibility regarding holding the school leader responsible for achievement, yet some states like the South Carolina Department of Education embeds student achievement in all 10 of the principal evaluation standards titled Program of Assisting, Developing, and Evaluating Principal Performance (PADEPP). For example, Standard 3, describes school leaders' responsibility for ensuring that each student has equitable access to highly effective teachers, learning opportunities, academic and social support, and other resources necessary for success. In Standard 9 (SCDE, 2017), the focus on performance outcomes is evident as

The principal develops and implements an appropriate annual professional development plan on the basis of three required areas: identified strengths and weaknesses, the district strategic or school renewal plan, and area(s) for student growth. For each of the three goals, principals must develop an action plan and monitor their progress towards meeting those goals (p. 8).

\section{Limitations in Research Priorities: Accountability and the Role of Research and Evidence}

Symptoms stemming from a long history of inequitable practices, perceptions, and policies include the evident gaps in opportunities and academic achievement. The policy context in South Carolina illuminates challenges for educational professionals in K-12 and higher education. These include accountability requirements and delimitations with research priorities.

To mitigate the inequities, researchers and policymakers in the U.S. and in other countries promote scientific evidence-based interventions. The effectiveness of these interventions is typically measured by standardized tests and empirical research that use randomized controlled trials (RCT), quasi-experimental designs (QED), regression discontinuity designs, and single-case designs. Consider the federal law, the Every Child Succeeds Act (ESSA) of 2015. It encourages school districts to use federal funds to support evidence-based interventions. While we argue 
there is value in the use of evidence from quasi-experimental or randomized control designs, we also argue that a hyper-focus on these studies limits the learning that could happen from other types of research focus and goals. Unfortunately, the way policy and research funding is currently focused, limited explicit attention in these types of measurement is focused on values that can drive promising practices, including humanistic values (Dewey, 1916), or culturally responsive (e.g. Scanlan \& López, 2012), or those that value mutualistic research-practice-partnerships (RPPs) (Coburn \& Penuel, 2013), or those that center context to make educational decisions that are place-based (Dewey, 1916), or those that ask for whom does something work, when, and under what conditions (Cohen-Vogel et al., 2015). Instead, neoliberal pressures for competition and achievement exacerbate the pressures for researchers and school leaders, especially those in low performing educational contexts. Funding for educational research endeavors reflect this trend. Educational reform tends to focus on the improvement of students' performance outcomes, which can be seen in how and where the Office of Educational Research and Improvement (OERI) have awarded their funding. Since 2002, 75\% of the education research funded by OERI addresses causal questions using random assignment design compared to prior randomized controlled trials which constituted only $5 \%$ of the federal funding (Morrison, 2012).

Recent U.S. education policies have moved toward "scientific" evidence-based practice. Policy documents under both Republican and Democratic administrations from the No Child Left Behind Act (2002) to more recent Race to the Top (2008) have reflected the importance of evidence from externalized evaluations to guide school decisions. The U.S. Department of Education now requires researchers applying for grant funding to demonstrate that their research designs are based upon prior studies with "strong evidence" explicitly defined by large-scale quantitative studies with randomized controlled trials or quasi-experimental designs. Internationally, multinational organizations, such as the Organization for Economic Co-operation and Development (OECD) and the World Bank, have also made evidence-based policymaking a priority both in their own work as influential research and policy organizations as well as for their members (Wiseman, 2010).

Researchers have also argued for the use of natural scientific evidence to inform educational practice (Eisenhart, 2005; Hattie, 2008; Schneider et al., 2007; Slavin, 2008). While scientific evidence-based interventions which link research to practice are useful, we see limitations in the lack of traditional humanistic values of education for growth and democracy (e.g. Dewey), cultural diversity, and contexts. In Democracy and Education, Dewey (1916) argued that an education which only emphasized the achievement of "external aims," (e.g., standardized tests) hinder students' and teachers' capacities for continuous growth and leads them toward viewing learning as an overly burdensome activity which they should seek to end as quickly as possible. Drawing on Dewey, Biesta (2010) argues, "Calling the idea of value-based education an alternative is not meant to suggest that evidence plays no role at all in value-based education but is to highlight that its role is subordinate to the values that constitute practices as educational practices" (p. 493). Biesta's 
critique of evidence-based reforms is supported by research on culturally responsive leadership.

Culturally responsive leaders are not only aware of the increasingly diverse student demographics, but they respond to the changes through culturally responsive practices. These leaders strive to develop teachers who legitimize students' funds of knowledge and acknowledge the histories of students through their teaching (Gay, 2002). Thus, culturally responsive leaders encourage their teachers to utilize the knowledge of their students' culture and their knowledge of the dominant culture to construct intercultural bridges that acknowledge differences "without shining the deficit light on students' cultural knowledge" (Ladson-Billings, 2009, p. 18). Moreover, culturally responsive leaders recognize the impact of deficit thinking on student learning and work to remove those and other barriers.

\section{Aim of the Two Initiatives: LEI and SITIS}

The two initiatives featured, LEI and SITIS, offer a counter narrative to making school improvements through a greater focus on development and improvement by prioritization of humanistic values and continuous improvement. Further, this work is done through two types of partnerships, where both help educational professionals (1) build internal professional capacity to address problems of practice, (2) strengthen human connections both within the school as well as with the community, and (3) improve instruction through improving their students' experiences.

\section{Conceptual Model for the School Development Projects in South Carolina}

We draw on a conceptual model developed by Ylimaki et al. (2019). Ylimaki et al. (2019) argue, "as U.S. schools are becoming increasingly diverse, we see a need to renew a focus on humanistic education values, including a focus on culturally responsive practices that support increasingly diverse students in schools" (p. 17). Therefore, the authors argue for the need to balance scientific evidence-based values and humanistic education values. Scientific evidenced-based and humanistic values are at tension; however, with reflection and pedagogical activity there can be a balance. Culturally responsive practices consider the diversity of the students and incorporate the values and cultural funds of knowledge in pedagogical activity in the classroom (Ylimaki et al., 2019; Ylimaki \& Jacobson, 2013).

This is in line with the continuous improvement framework of improvement science, which is anchored by six principles of improvement for education: (a) "Make the work problem-specific and user-centered"; (b) "Variation in performance is the core problem to address"; (c) "See the system that produces the current outcomes"; 
(d) "We cannot improve at scale what we cannot measure"; (e) "Anchor practice improvement in disciplined inquiry"; and (f) "Accelerate improvement through networked communities" (Carnegie Foundation for the Advancement of Teaching, 2020). Terms like user-centered, system, and networked improvement communities invite a humanistic approach to interventions, improvement and research while also valuing measurement and data as a way to guide improvement efforts.

\section{Leadership and School Development Project 1: Lowcountry Educators Initiative (LEI)}

The LEI was modeled after the previously implemented, research-based, and studied Arizona Initiative for Leadership Development and Research (AZiLDR) project. AZiLDR focused on four-prongs of improvement: leadership, education, and school development as well as its delivery system (Cohen et al., 2002; Garet et al., 2001; Wenglinsky, 2000; Ylimaki et al., 2019). The AZiLDR project was developed to assist persistently underperforming, culturally diverse schools and increase the capacity for continuous school improvement. In the design of AZiLDR, school team members (teachers, administrators, and coaches) got the chance to use evidence or data as a source of reflection and continuous growth, drawing on what has worked in the past and trends across various sources of data to develop plans for future improvement. Professional development such as coaching meetings, institutes, and/ or improvement team meetings offered opportunities for participants to reflect on the assets of their communities thoughtful and in culturally responsive ways, leveraging these strengths to improve practice.

Place-Based Education The LEI introduced the teachers to placed-based education, a form of experiential education, where learning is grounded in the resources and values of the local context. John Dewey (1916) promoted the importance of experiential education in relation to the local context. Place-based education typically includes outdoor education methodologies as advocated by John Dewey to help students connect with their particular locality. As noted by Dewey (1916), an education which only emphasizes the achievement of "external goals" (e.g. standardized test scores, grades, school letter grades, etc.) hinders students' and schools' capacities for continuous growth and leads them toward learning as an overly burdensome activity which they seek to end as quickly as possible.

\section{LEI Participants}

The LEI involved participants who were employed at multiple layers of the educational organization. Participants were from multiple school districts and worked at the school level and the district level. Within South Carolina there are extreme 
variations in the economic resources depending on the school district where the students attend school. Of the five school districts that had attendees at the LEI, three school districts had a poverty index of $90 \%$ or higher (NCES, 2019c). Hampton 2 and Barnwell 19 had a poverty index of $91 \%$ and Allendale had a poverty index of 94\% (NCES, 2019c). One school district had a poverty index of $76.04 \%$ and the other school district had 58.32\% (NCES, 2019c). The five school districts that attended the LEI were not only some of the most economically challenged in the state, but the one school district had a graduation rate of $76.54 \%$ (NCES, 2019a). The other four school districts with attendees at the LEI had graduation rates of $83.94 \%, 87.13 \%, 88.33 \%$ and $89.35 \%$ (NCES, 2019b).

The LEI targeted thirty rural teachers who worked in the region of the state known as the lowcountry. Participants were invited from six counties: Beaufort, Allendale, Jasper, Hampton, Colleton and Barnwell. Most of these districts are located in economically challenged and underdeveloped rural communities, known as the aforementioned "corridor of shame". The majority of the schools within these districts are severely resource constrained as a result of declining state funding and diminishing tax bases as businesses leave the area. While many of these issues require national and state level responses, one key focus of the LEI was to help educators within these districts identify and leverage their local resources.

The LEI Participant Demographics The LEI participants were drawn from Beaufort, Colleton, Hampton and Jasper counties. The 30 participants had spent an average of 7.79 years teaching at their current school, 9.74 years teaching in the rural schools in the lowcountry and 4.6 years teaching in rural schools outside of the lowcountry. In contrast, they spent an average of 2.85 years at a non-rural school, although $66 \%$ of participants indicated that they had no teaching experiences in such locales and about $17 \%$ had less than 5 years' experience teaching in non-rural settings. The majority $(63.63 \%)$ of participating educators were from elementary schools, although there was also representation from middle $(12.12 \%)$ and high schools (15.15\%), and the district office (6.1\%).

To provide further context about their daily work lives, participants noted that they traveled an average of 18.23 miles in their commute from home to work. While most indicated only having to travel 1-10 miles to work, a significant portion of participants traveled more than 60 miles to work daily.

\section{Implementation of the LEI}

First, meetings took place with school superintendents in the lowcountry to learn the needs of the area. After the initial meeting we developed the Lowcountry Educator Institute (LEI). Specifically, LEI used the lessons learned from Arizona to help educators better understand what is available in the rural community and how to better leverage these resources to build on the capacity of the local education system. While some aspects of rural living and rural communities have been 
described in deficit terms in the media and elsewhere (e.g. lack of economic diversity; slow internet speed; long distance to urban/suburban commerce, lack of social life, and recreational opportunities), the LEI aimed to change the narrative as it values what the communities do have: a strong sense of community, K-12 schools serving as a cultural hub, little traffic/congestion, low cost of living, and a sense of pride in supporting locally owned and managed business in rural communities.

In the summer and the fall of 2018, the team implemented the LEI centering around two major themes: (1) building the capacity and sustainability of local rural educators and (2) familiarizing educators with local resources. Thus, LEI sought to highlight the advantages and resources of the lowcountry communities. It provided the tools to encourage students and teachers to appreciate the area and tap into its agricultural, tourism and historical resources. The LEI helped the teachers better connect to their students as well as other teachers. A similar theme of connection will be described later in the SITIS portion of the chapter.

The LEI provided the tools to encourage teachers to appreciate their local community and tap into its resources in to two sessions. The first session of the LEI was held in early August 2018. At the start of the session participants used words like "country," "agriculture," "small towns," and "farms" to describe rurality. While these descriptions are primarily neutral, several connoted rurality with negative descriptors such as "less resources," "an area away from major development and amenities" "lots of unused land, limited development, poverty and low income earners", and "less things to do, less attractions." Only $39 \%$ of responding participants indicated that they had heard of (although may not understand) the term place-based education, and an even lower percentage (25\%) of the participants were not familiar with the term place-based education.

The LEI provided training and curriculum for rural teachers so that they could better introduce their students to the possibilities of science and agriculture-related careers. During the September 2018 follow-up session, teacher participants presented how they planned and implemented place-based education in their schools. Some teachers from the same school presented in teams, while others developed individual lesson plans.

We conducted a mixed methods evaluation, including a survey and semistructured interviews with a random selection of participants. Further, we collected and analyzed artifacts from the participants' projects. The LEI activities were grounded in effective professional development research (Cohen et al., 2002; Garet et al., 2001; Wenglinsky, 2000). Garet et al. (2001) study, endorsed by the What Works Clearinghouse, was the first large-scale empirical comparison of effects of different characteristics of professional development on teachers' learning.

Results of the evaluation indicate that there are more positive outcomes from professional development activities when all the structural features (form, duration, collective participation) and the core features (content focus, active learning opportunities, coherence) are included. These findings align with prior professional development research. Desimone et al. (2002) conducted a national mixed methods research study of curriculum directors to examine implementation strategies to diffuse professional development content throughout schools. Building on the earlier 
work of Garet et al. (2001) the study by Desimone and her colleagues (Desimone et al., 2002) suggests three additional characteristics of high quality professional development include: (1) alignment to standards and assessments, (2) continuous improvement efforts, and (3) involving teachers in the planning. Wenglinsky (2000) conducted a multi-level structural equation modeling of NAEP data and the relationship between teachers' professional development and eighth-grade achievement scores. Specifically, Wenglinsky (2000) found that extended periods in professional enhancement activities are closely linked to effective classroom practice. Furthermore, results indicated that significant gaps among teachers in their professional development contribute to differences in teacher quality, which substantially impact on student achievement, especially with the most disadvantaged students.

\section{Findings: Participant Projects and Application of Place-Based Education}

There was a range of understanding of implementation of place-based education. Some of the teachers truly embraced place-based education and developed and implemented effective place-based lessons for their classes.

Examples of Place-Based Design One of the teachers from Allendale-Fairfax involved the superintendent and school principal who were supportive of placebased education. The high school principal works in a rural area surrounded by cotton fields but had yet to see cotton up close. The teacher taught the school principal about cotton. Many teachers drove by cotton fields to get to school, but they had never touched a cotton pod. He stated, "place-based education is a necessary element in our schools today more than ever." Like the principal, the students had not seen cotton up close. They thought cotton was still handpicked and that farmers would water with a garden hose.

The teacher also involved eight community farm leaders who were willing to work with the school. To advertise the farmers coming to school, the teacher involved the technology teacher to create posters and electronic media to advertise the farmers and other community members such as EMT and firefighters coming to school. The farmers came to school and educated the students on how technology is used for farming. The farmers also helped the students create a school garden. This teacher really understood the goals of place-based education and he not only impacted his classroom, he impacted the whole school.

A group of teachers from an elementary school organized a field trip to a local pumpkin patch where the students learned the entire life-cycle of a pumpkin. The lesson plans and the field trip also included the students learning about farm animals such as pigs, cows, horses, and goats. While on the field trip, the students also learned about the life cycle of animals and what each of the animals produces. The 
students would also learn about the production of hay from growing, to bailing and to use of hay. Due to the training one of the teachers said that she has a greater appreciation and greater awareness of local farms and farmers. She really valued getting to meet one of the local farmers at the training.

One of the teachers started a school garden to teach students about growing vegetables, but this year she added a composting component so students learn to preserve their community by taking care of the land and water. In addition, she asked a developer to aid the students in creating a walking tour for their town of Bluffton. The students got to explore their town to create the walking tour. One of the teachers stated that she would use Beta Club to clean historical sites in their community.

Example of Principal Support for Place-Based One principal attended LEI with eight of her teachers. This principal embraced the learning, as she led by example in her school. She conducted the back to school staff development off campus at Lake Edgar Brown and Barnwell State Park, which is approximately ten miles from the school. By conducting the staff development at a local site, she taught the teachers what they can do to use the resources in their part of the state to enhance the students' learning. Since the school is Title One and $79 \%$ live in poverty according to the South Carolina 2016-2017 school report card poverty index, the principal knows that the parents do not have a lot of money for field trips, so learning about the community is beneficial. The principal even worked with transportation to reduce the cost of the school buses to take the students to the local sites.

From the initial training, the entire fifth grade level developed a unit based off a field trip to Lake Edgar Brown and Barnwell State Park. Prior to the place-based education institute, the big field trip for fifth grade was going to Barrier Island, but due to resources the class could only take 60 of the 200 fifth grades. The teachers realized that they could take all of the fifth graders to two sites by selecting to stay local. By taking the students off campus, the students were able to apply their learning to their own local communities.

While on the local field trip, the students also were exposed to science and math involved in road construction. One of the teachers said that the most valuable takeaway from the training was "integrating the classroom experiences into the wider community." One fifth grade teacher shared that place-based education "gets kids involved in real problem solving that is relevant to their community." The students can make connections between abstract science concepts to the local lake or apply math problems in solving community issues like measuring how much fencing needed to be purchased to mark the parking lot at Barnwell State Park. The evidence showed that the teachers approach lesson development and instructional design differently after attending the conference as they are thinking how they can relate the content standards to the students' community.

In fourth grade, the teachers organized a field trip to the local news station and local museum. The students learned about weather phenomena from meteorologists from a local news station. After learning about weather phenomena, the students then saw the path of destruction from a tornado that occurred at the Barnwell State Park. While in the park the teachers designed lessons to incorporate weather, the 
water cycle, and shadow movements. The fourth-grade teachers understood the concept of place-based education and designed lessons that would effectively implement place-based education.

A benefit from several teachers from the same school attending LEI is that regular education and special education teachers had the opportunity to plan together. The sixthgrade teachers and the special education teacher created place-based education lessons to incorporate all learners. Part of place-based education was to get to know the culture of the students who are attending the school. In the special education classes, the students were to share about their culture by sharing about an heirloom or something that was passed down from generation to generation. One student brought in a photo of his house. He shared how his great grandfather built the house and now his family is living there. The students learned about their families as well as the communities in which they live. The principal wants to continue to approve and support place-based experiences for the students at her school. The culture at the school has changed as teachers are looking for ways to connect all learning to place-based learning.

Increased Understanding of Place-Based Education Results of the evaluation indicate that participants gained a better understanding of place-based education and assets of the rural community. We also verified the importance of school teams for implementation and sustainability as well as positive outcomes from professional development activities when all of the structural features (form, duration, collective participation) and the core features (content focus, active learning opportunities, coherence) are included. Some schools were represented by only one teacher while others had large teams of teachers. As mentioned earlier, one principal attended alongside her teachers. The results as presented by the participants clearly illustrated the need for working as a team. Specifically, we recommend training for school leadership teams to include the principal, teacher leaders, and a district representative. This team composition will allow teams to plan for diffusion of the concepts/practices throughout the schools.

Further, while valuing inclusion of teacher assistants in the training, their ability to deeply apply the learning was predicated by the support from teachers and school leaders. For future institutes, participants commonly suggested more specificity and lesson modeling/ideas on how to link place-based education into lesson plans for more subject matters and methods to overcome barriers for implementation, such as "how to deal with less than enthusiastic administrators as making a reasonable chance..." for teaching place-based education in their classrooms.

\section{Leadership and School Development Project 2: School Improvement Through Improvement Science (SITIS)}

The SITIS involves the development of a university-district partnership centered on addressing a problem of practice: the achievement gap between the students of color and the white students. This focus area for improvement was originally identified by 
the school district and confirmed as a problem by school leaders, and is evidenced by assessment data.

The partnership began from an opportunity to participate in an initiative, initially designed to bring university-district partnerships together to use and infuse improvement science practices in educational leadership preparation programs in order to be more effective in developing the school leaders of today and tomorrow. Improvement science is a type of continuous improvement that prioritizes root cause analyses, planning and testing, then scaling changes in a systematic way (see e.g., Bryk et al., 2015). An improvement science framework also values the local context as a source of expertise and as a locus for change.

\section{SITIS Participants}

The partnership consists of stakeholders affiliated with the university (e.g., faculty) from the College of Education. The university is a large, public research intensive university. The school district has four high schools, three middle schools, and sixteen elementary schools and is in a city, but is isolated and surrounded by a very rural area. The district is located about an hour and a half drive from the university. At the inception of the partnership it was anticipated that multiple schools within the district were to participate in improvement work. However the reality of the contextual factors (e.g., leadership churn) led to the participation of faculty from one university department and one committed school leader - a first year principal named Dana. Partnering with one school is aligned with the spirit of improvement science, where tests and trials start small. The partnership between the school and the university department shares an explicit priority of educational equity for all students.

Dana has worked at Woodlawn High School for multiple years, but the beginning of the university-district partnership was the same year she began her leadership position. Woodlawn serves about 1700 students in grades nine through twelve. Fifty-six percent of the students are Black and $44 \%$ are White students. The certified teaching staff is approximately $33 \%$ teachers of color and $67 \%$ White and the noncertified staff is $75 \%$ of color and $25 \%$ White.

The partnership work prompted the creation of a school-based improvement team who would spearhead the school-based work learning and using improvement science. This group was organized purposefully by Dana and consists of five fulltime classroom teachers, each representing different content areas. One administrator (i.e., the principal) is also a member of the team. The team is made up of all women. Four are Black and two are White. From the university-side of the partnership, multiple faculty members are involved and between two and four faculty members typically attend each meeting at the partner school. The university faculty involved include three white women faculty members and four men of color. More about the work of the improvement team will be described in the next section. 


\section{Implementation of the SITIS}

Although the partnership technically began before the organization of the formalized improvement team at the school, for the purposes of this chapter, the information about the progress and learning of the work begins after the improvement team was formed. The school-based improvement team involves five teachers and a building administrator. The teachers were purposefully selected by the administrator and she invited teachers who were well-respected. The partnership typically meets monthly and each meeting at this stage is dedicated to understanding an identified problem of practice. Determination of the focus problem has been a journey. Focused on a value of equity, the team, at the overarching level, is focused on closing opportunity and achievement gaps between students of color and white students. However, the complexity of addressing this problem calls for an examination of the causes of the problem and how the problem manifests in schools. The team used focused brainstorming and questioning activities to examine the problem and what might be contributing to it. Often, when attempting to address educational challenges, such as test scores and other indicators of achievement, educational professionals put together an intervention to help increase test scores (e.g., a reading comprehension program), implement it "with fidelity", and then observe what happens. However, this approach is vulnerable to the threat that the proposed intervention is addressing a symptom of the problem and not an underlying issue leading to the symptom connected to the problem.

In efforts to push against this threat, the improvement team used tools such as brainstorming then using their input to organize thematically the brainstormed ideas into a fishbone diagram. Recall that the LEI helped the teachers better connect to their students, as well as other teachers, strengthening the capacity of the community in the process. The SITIS team, with an overarching aim to address the achievement gap, is similarly focusing their efforts on relationships and connections in their building. Their current theory of improvement is that if there is a genuine connection between teachers and students, then the educational professionals will be able to cultivate and contribute to a positive building culture, will be able to improve their practice (e.g., training and development on mitigating racial biases and/or culturally-responsive teaching), and then students will be better positioned to find a higher level of educational opportunity and success. In line with a tenet of improvement science that reminds improvers that our understanding and identification of a cause of a problem is "possibly wrong and definitely incomplete" (Russell et al., 2015, p. 35) and to gather additional understanding, the team also conducted empathy interviews so that they may understand the problem from other stakeholder groups' perspectives while also gathering data on if the team is focusing their improvement efforts on the right area. For example, they interviewed students to learn how connected they felt to the school and the teachers. In summary, the team is currently using qualitative and quantitative data to help make sense of the phenomena of focus and is willing to identify the specific places to target efforts for improvement. 
It is important to note that this work is within an intentional partnership. It is driven by the expertise at the school with the school improvement team and is supported by the university faculty who serve in reflective and guiding roles since the school team is simultaneously learning about how to use an improvement science approach while engaged authentically in this work. Future directions will blend the expertise of those at the local site with other sources, such as existing previously published research. What will not happen is a rapid, wholesale adoption of an intervention that has evidence of success somewhere else. However, learning from other successful models or approaches (e.g., culturally-responsive teaching and leadership) will be utilized, shaping the action steps of the team in ways appropriate for their context.

There is a critical ingredient to the partnership and that is the leadership at the school. Dana's role cannot be overstated. In this initiative, Dana was the critical leadership lever who shepherded the work. Without her insights, commitment, and willingness to try a new approach to address problems of practice within her context, the work would not have progressed and likely would not have even truly begun. She demonstrated, and continues to demonstrate, different leadership qualities that have been particularly helpful. She was explicitly enthusiastic about the work and communicated this commitment to her team. Her intentional selection of the team members demonstrated her recognition of the types of talent needed for this work, her belief in, and her observation of the selected teachers' reputations within their school community that would position them well for this continuous improvement work focused on equity. This is an important note since "as an organizational trait, positive efficacy beliefs in the capacity of the collective provide a boost to teachers' morale, tenacity, and resilience as they pursue increasingly ambitious student outcomes, rendering themselves likely to achieve their goals" (Forman et al., 2018, p. 185).

The improvement science approach is an alternate framework that will yield findings, that may not include experimental designs. Other researchers such as Lewis (2015) and Cobb and Virella (2019) propose that some data and research cannot appropriately address problems that schools, each with unique context, aim to improve. The SITIS work is approaching school improvement that utilizes prior research while leveraging the context in order to understand and determine appropriate change ideas to help meet their aim of closing the opportunity gap between their students of color and white students so that the achievement gap will also close.

\section{Recommendations for Practice}

The programs implemented offer evidence for (1) providing leadership support for school improvement efforts (2) the use of local context in improving practice and (3) the valuing of various data to engage in locally-relevant and appropriate work. 


\section{Leadership Support}

Our observations of the role that leadership support plays aligns with prior research. Just as Halverson and Kelley (2017) point out, the "principal's leadership works by engaging and building leadership capacity throughout the school" (p. 12) and that "the principal's role shifts to creating supporting structures..." (p. 14). Leadership support, in the challenging work of educational improvement, will be critical. Support from school and district leadership comes in the form of valuing approaches to learning such as place-based instruction or approaches to addressing problems of practice, such as improvement science. Actions that convey support include, but are not limited to (a) attending professional development with teachers, (b) participation on the improvement team, and (c) allowing teachers to make decisions, try new approaches, and provide resources (e.g., time, space) to meaningfully engage in the work.

In the LEI, the most successful place-based designs were those that had support from the school and district leaders. With SITIS, the principal is an integral part of the improvement team providing necessary support and leadership. Leadership can come from different sources. On some occasions, leadership may come from the district level, while in others, school-level leadership may be a primary driver of the work.

\section{Using the Local Context in Improving Practice}

Prior research highlights challenges teachers face when working to improve practice. In the LEI, the valuing of the local context not only changed instructional practice, but also was changing the narrative of living, working, and learning in a rural context to an assets-based approach, valuing and leveraging the resources and benefits of rural communities. It focused on local connections and relationships to be cultivated to provide a high-quality education for students. The SITIS improvement team, due to the insights and experiences of the educational professionals who were included on the team, also focused on the relationships and connections to impact the educational experience of students. Looking to the resources and knowledge already available in a local site and building off of those strengths provide opportunities for educational improvements due to the appreciation of the context.

\section{Valuing of Data}

The fourth principle of the Carnegie Foundation for the Advancement of Teaching's Six Core Principles of Improvement (2020) argues, "We cannot improve at scale what we cannot measure" and goes on to state, "Embed measures of key outcomes 
and processes to track if change is an improvement. We intervene in complex organizations. Anticipate unintended consequences and measure these too" (para. 4). Data are critical in improvement work. Gathering and organizing data offers guidance to what is or is not working, for whom, and under what conditions (CohenVogel et al., 2015). We argue, as others have (e.g., Lewis, 2015), that research in educational improvement broaden the acceptance of which types of data typically hailed (such as RCTs) and also value data that provides information to catalyze the ability to scale improvement efforts, such as context-specific, value-focused, and humanistic data.

\section{Recommendations for Policy}

The U.S. and South Carolina have had an extremely long and shameful history of educational inequities based on race and class. For years, many interventions with goals of addressing and mitigating challenges such as the student achievement gap have not found wide success. We, through the success of AZiLDR and its successor, LEI, used humanistic, values-based approaches to improvement-demonstrated positive changes in teacher mindsets and practice. SITIS, although too soon to report changes in instruction, is similarly using local expertise to harness changes. Through the centering of the local context in place-based education and improvement science approaches to educational improvement, we recommend that this type of prioritization be valued in research design, research funding, and educator preparation.

The work described in this chapter was and continues to be done through partnerships between schools and universities. This type of professional relationship requires the distribution of decision making and collective learning (Goldring \& Sims, 2005). Through different types of partnering, both the LEI and SITIS helped educational professionals (1) build internal professional capacity to address problems of practice, (2) strengthen human connections both within the school as well as with the community, and (3) improve instruction through improving their students' experiences. López Turley and Stevens (2015) argue that public schools and universities can both benefit from partnerships especially as these institutions face increased accountability despite budget cuts.

Findings noted the importance of leadership, of the local context and data. Therefore, policy to support leadership could include components such as partnerships, developing robust connections to the community in which they live, the value of continuous improvement when addressing problems of practice, and offering the latitude for school leaders to be able to engage in ways outside of what has traditionally been done to push on the status quo to forward a more equitable school environment. Further, the role of context and data is embedded in continuous improvement and root cause analysis work where improvers interrogate why and for whom something is working or not working and under what contextual conditions (Bryk et al., 2015). 
As organizations that want to value improvement and place-based learning embark on this work, they will likely come across some institutionalized factors that do not fully align. For instance, the mechanisms in place for leadership assessment and feedback across different states may want to consider how elements such as these are infused into their evaluative practices. For example, Standard 5 in the principal evaluation system in South Carolina called the Program for Assisting, Developing, and Evaluating Principal Performance (PADEPP) is focused on School/ Community Relations. The LEI study findings provide evidence that would invite policymakers to evaluate the wording to explicitly encourage the school to not only invite the community in, but also encourage school and district leaders to cross the traditional school and district boundaries to engage with the community in the community.

Standard 9 is focused on Principal Professional Development. From our work in the LEI and SITIS, engagement with the various stakeholders is critically important. Thus, principals who look to various stakeholders (i.e., the "users" of education and those who experience education) to help determine where professional learning resources should be targeted are arguably aiming to be improvers and effective school leaders. Building principals should be supported and allowed to make professional learning choices and goals that fit their unique context, since they are positioned to know their context more intimately than those who work outside of the school building - in central office, for example.

The relationship that the district has with the university can also help shape institutions of higher education. Educational leadership preparation programs can help forward some of the key findings and practices presented in this chapter. Curriculum, coursework, and activities could offer powerful learning experiences including authentic opportunities for leadership candidates to practice meaningful engagement and relationship building with internal and external educational stakeholders (Cunningham et al., 2018). Preparation programs are also well-positioned to help future school leaders in their approach to addressing problems of practice though ongoing support, guidance, and the continuous bridging of theory to practice (Sanzo et al., 2011).

Leadership preparation programs or other leadership professional development programs should also help leaders be successful in meeting the professional standards referenced above. Professional development should be centered on how to identify problems, deeply understand problems, and how to systematically address problems of practice in a way that is appropriate for their own context in a continuous improvement framework.

Policy could serve as a legitimizing level in articulating support, funding, and research designs that values approaches to educational improvement that are not traditionally prioritized, such as continuous improvement with its recognition of the important role of context, as the place-based education also recognizes. The prioritization of positivist, large-scale quantitative research has not yet provided the panacea that the public is in search of. We argue that an intervention tested and then implemented in other contexts with fidelity is not necessarily the way to "achieve" educational equity and improvement. Addressing problems of practice in ways 
beyond What Works Clearinghouse, for example, will support the field of education in its pursuit of improving education so every student is offered a high-quality and impactful experience. The work in the LEI and SITIS is exploring a new way of thinking about approaches to teaching and approaches to addressing problems of practice. It is much more focused on shifting the way we conceptualize and interpret the work rather than implementing a "thing". These initiatives challenge educators to reflect deeply about the work, the context, and why something exists in order to appropriately move forward.

\section{References}

Biesta, G. J. J. (2010). Why 'What Works' still won't work: From evidence-based education to value-based education. Studies in Philosophy and Education, 29, 491-503.

Black, D. W. (2017). Kids will suffer because court refused to do its duty. The State Newspaper. Retrieved from https://www.thestate.com/opinion/op-ed/article186489863.html

Bryk, A. S., Gomez, L. M., Grunow, A., \& LeMahieu, P. G. (2015). Learning to improve: How America's schools can get better at getting better. Harvard Education Press.

Carnegie Foundation for the Advancement of Teaching. (2020). The six core principles of improvement. Retrieved from https://www.carnegiefoundation.org/our-ideas/ six-core-principles-improvement/

Cobb, C. D., \& Virella, P. (2019). The legitimization of improvement science in Academe. Retrieved from https://pdfs.semanticscholar.org/2cf4/685d3b2e0459a63bea79f99a710e645903ee.pdf

Coburn, C. E., \& Penuel, W. R. (2013, January). Research-practice partnerships at the district level: A new strategy for leveraging research for educational improvement. Wiilliam T. Grant Foundation.

Cohen, D. K., Hill, H. C., \& Kennedy, M. (2002). The benefit to professional development. American Educator, 26(2), 22-25.

Cohen-Vogel, L., Tichnor-Wagner, A., Allen, D., Harrison, C., Kainz, K., Socol, A. R., \& Wang, Q. (2015). Implementing educational innovations at scale: Transforming researchers into continuous improvement scientists. Educational Policy, 29(1), 257-277.

Conroy, P. (1972). The water is wide. Dial Press Trade.

Cunningham, K. M. W., Van Gronigen, B. A., Tucker, P. D., \& Young, M. D. (2018). Using powerful learning experiences to prepare school leaders. Journal of Research on Leadership Education, 14(1), 74-97. https://doi.org/10.1177/1942775118819672

Desimone, L., Porter, A., Birman, B., Garet, M., \& Yoon, K. (2002). How do district management and implementation strategies relate to the quality of the professional development that districts provide to teachers? Teachers College Record, 104(7), 1265-1312.

Dewey, J. (1916). Democracy and education. The Free Press.

Eisenhart, M. (2005). Hammers and saws for the improvement of educational research. Educational Theory, 55(3), 245-261.

Forman, M. L., Stosich, E. L., \& Bocala, C. (2018). The internal coherence framework. Harvard Education Press.

Garet, A., Porter, A., Desimone, L., Birman, B., \& Yoon, K. (2001). What makes professional development effective? Results from a national sample of teachers. American Educational Research Journal, 38(4), 915-945.

Gay, G. (2002). Preparing for culturally responsive teaching. Journal of Teacher Education, 53(2), 106-116. 
Goldring, E., \& Sims, P. (2005). Modeling creative and courageous school leadership through district-community-university partnerships. Educational Policy, 19(1), 223-249. https://doi. org/10.1177/0895904804270777

Halverson, R., \& Kelley, C. (2017). Mapping leadership: The tasks that matter for improving teaching and learning in schools. New York, NY: John Wiley \& Sons.

Hart, L. C. (2015). Abbeville County School District v. State of South Carolina: How did we get here and what happens now? Retrieved from http://scasbo.net/wp-content/uploads/2015/11/1Abbeville-vs-State-of-SC-Laura-Hart.pdf

Hattie, J. (2008). Visible learning: A synthesis of over 800 meta-analyses relating to achievement. Routledge.

Ladson-Billings, G. (2009). The dreamkeepers: Successful teachers of African American Children (2nd Ed.). San Francisco: Wiley Publishers.

Lewis, C. (2015). What is improvement science? Do we need it in education? Educational Researcher, 44(1), 54-61. https://doi.org/10.3102/0013189X15570388

López Turley, R. N., \& Stevens, C. (2015). Lessons from a School District-University research partnership: The Houston education research consortium. Educational Evaluation and Policy Analysis, 37(1_suppl), 6S-15S. https://doi.org/10.3102/0162373715576074

Morrison, K. (2012). Causation in education research. Routledge.

National Center for Education Statistics. (2019a). Graduation rates. Retrieved from https://nces. ed.gov/ccd/tables/ACGR_RE_and_characteristics_2015-16.asp

National Center for Education Statistics. (2019b). High school graduation rates. Retrieved from https://nces.ed.gov/fastfacts/display.asp?id=805

National Center for Education Statistics. (2019c). The Condition of Education 2019 (NCES 2019-144). Retrieved from https://nces.ed.gov/fastfacts/display.asp?id=16

National Center for Education Statistics (NCES). (2020). Reading state snapshot report. Retrieved from https://nces.ed.gov/nationsreportcard/subject/publications/stt2019/pdf/2020014SC4.pdf

Orfield, G., Ee, J., Frankenberg, E., \& Siegel-Hawley, J. (2016). Brown at 62: School segregation by race, poverty and state. Retrieved from https://civilrightsproject.ucla.edu/research/k-12education/integration-and-diversity/brown-at-62-school-segregation-by-race-poverty-andstate/Brown-at-62-final-corrected-2.pdf

Russell, J. L., Bryk, A. S., Dolle, J., Gomez, L. M., LeMahieu, P., \& Grunow, A. (2015). A framework for the initiation of networked improvement communities Jennifer. Teachers College Record, 113(12), 2897-2921. Retrieved from https://www.learntechlib.org/p/90771/

Sanzo, K. L., Myran, S., \& Clayton, J. K. (2011). Building bridges between knowledge and practice. Journal of Educational Administration, 49(3), 292-312. https://doi. org/10.1108/09578231111129073

Scanlan, M., López, F. V. (2012). How school leaders promote equity and excellence for bilingual students. Educational Administration Quarterly, 48, 583-625.

Schneider, B., Carnoy, M., Kilpatrick, J., Schmidt, W. H., \& Shavelson, R. J. (2007). Estimating causal effects using experimental and observational design. American Educational \& Research Association.

Slavin, R. E. (2008). Perspectives on evidence-based research in education-What works? Issues in synthesizing educational program evaluations. Educational Researcher, 37(1), 5-14.

South Carolina Department of Education. (2017). Expanded program for assisting, developing, and evaluating principal performance. Retrieved from https://ed.sc. gov/educators/school-and-district-administrators/collective-leadership-initiative/ expanded-program-for-assisting-developing-and-evaluating-principal-performance-guidelines/

Switzer, D. \& Green, R. P. (2016). Education. University of South Carolina. Institute for Southern Studies. http://www.scencyclopedia.org/sce/entries/education/

Tran, H., Aziz, M., \& Reinhardt, S. F. (2020). Rage against the Machine: The Legacy of Education Leaders' Valiant Struggle for Social Justice in Abbeville v. South Carolina. Journal of School Leadership. https://doi.org/10.1177/1052684619899612 
U.S. News. (2020). U.S. news and world report education rankings. Retrieved from https://www. usnews.com/news/best-states/rankings/education

Wenglinsky, H. (2000). How teaching matters: Bringing the classroom back into discussions of teacher quality. Educational Testing Service.

Wiseman, A. W. (2010). The uses of evidence for educational policymaking: Global contexts and international trends. Review of Research in Education, 34(1), 1-24.

Ylimaki, R., \& Jacobson, S. (2013). Comparative perspectives on leadership preparation for organizational learning, instructional leadership, and culturally responsive practice. Journal of Educational Administration, 51(1), 6-23.

Ylimaki, R. Brunderman, L. \& Moyi, P. (2019) Balancing evidence-based and humanistic education in school development for underperforming Arizona and South Carolina schools. Leadership and Policy in Schools. Retrieved from https://doi.org/10.1080/15700763.2019.1695850.

Open Access This chapter is licensed under the terms of the Creative Commons Attribution 4.0 International License (http://creativecommons.org/licenses/by/4.0/), which permits use, sharing, adaptation, distribution and reproduction in any medium or format, as long as you give appropriate credit to the original author(s) and the source, provide a link to the Creative Commons license and indicate if changes were made.

The images or other third party material in this chapter are included in the chapter's Creative Commons license, unless indicated otherwise in a credit line to the material. If material is not included in the chapter's Creative Commons license and your intended use is not permitted by statutory regulation or exceeds the permitted use, you will need to obtain permission directly from the copyright holder.

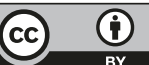

